\title{
Inadequate Triglyceride Management Worsens the Durability of Dipeptidyl Peptidase-4 Inhibitor in Subjects with Type 2 Diabetes Mellitus
}

\author{
Masashi Shimoda, ${ }^{1}$ Maiko Miyoshi-Takai, ${ }^{2}$ Shintaro Irie, ${ }^{1}$ Akihito Tanabe, ${ }^{1}$ Atsushi Obata, \\ Seizo Okauchi, ${ }^{1}$ Hidenori Hirukawa, ${ }^{1}$ Tomohiko Kimura, ${ }^{1}$ Kenji Kohara, ${ }^{1}$ Shinji Kamei, ${ }^{1}$ \\ Tomoatsu Mune, ${ }^{1}$ Kohei Kaku, ${ }^{2}$ and Hideaki Kaneto ${ }^{1}$ \\ ${ }^{1}$ Division of Diabetes, Metabolism and Endocrinology, Kawasaki Medical School, 577 Matsushima, Kurashiki 701-0192, Japan \\ ${ }^{2}$ Division of General Internal Medicine 1, Kawasaki Medical School, 577 Matsushima, Kurashiki 701-0192, Japan
}

Correspondence should be addressed to Masashi Shimoda; masashi-s@med.kawasaki-m.ac.jp

Received 20 February 2017; Revised 16 April 2017; Accepted 27 April 2017; Published 25 May 2017

Academic Editor: Kazuya Yamagata

Copyright ( 2017 Masashi Shimoda et al. This is an open access article distributed under the Creative Commons Attribution License, which permits unrestricted use, distribution, and reproduction in any medium, provided the original work is properly cited.

\begin{abstract}
Dipeptidyl peptidase-4 (DPP-4) inhibitors are often used all over the world and exert various beneficial effects including glucoselowering effect in many subjects with type 2 diabetes. It is poorly understood, however, which factors are closely related with the durability of glucose-lowering effect by DPP-4 inhibitor. In this study, we examined retrospectively which factors could mainly influence the durability of DPP-4 inhibitor. We enrolled 212 participants with type 2 diabetes to whom DPP-4 inhibitor was administered for over 1 year without an addition or increase of other hypoglycemic agents. Age and baseline HbAlc level were significantly higher in the effective group than those in the ineffective group. The effective group had a tendency of smaller amounts of weight change, average total cholesterol, and average triglyceride compared with the ineffective group. Multiple logistic regression analysis showed that average triglyceride and baseline $\mathrm{HbAlc}$ were independent predictors associated with the durability of DPP-4 inhibitor. Moreover, an average triglyceride level contributed to the durability of DPP-4 inhibitor in the obese group (BMI $\geq 25 \mathrm{~kg} / \mathrm{m}^{2}$ ) but not in the nonobese group (BMI $<25 \mathrm{~kg} / \mathrm{m}^{2}$ ). These results suggest the importance of strict triglyceride management to maintain the durability of glucose-lowering effect by DPP-4 inhibitor, especially in obese subjects with type 2 diabetes.
\end{abstract}

\section{Introduction}

The pathophysiology of type 2 diabetes is characterized by relative insulin secretory failure against insulin resistance. It is widely accepted that $\beta$-cell function progressively deteriorates in individuals with type 2 diabetes mellitus as previously shown in the UK Prospective Diabetes Study [1]. There is some variation in pancreatic $\beta$-cell response to various stimuli (e.g., insulin resistance, increased metabolic load, and systemic inflammation) among individuals, not only due to the difference of genetic susceptibility but also due to environmental stress such as inflammatory stress, endoplasmic reticulum stress, metabolic and oxidative stress (e.g., glucotoxicity, lipotoxicity, and glucolipotoxicity), amyloid stress, and loss of islet cell integrity [2].

The incretin hormones, glucagon-like peptide-1 (GLP-1) and glucose-dependent insulinotropic polypeptide (GIP), are secreted from the gastrointestinal tract along with the digestion and absorption of nutrients and promote glucosedependent insulin secretion from pancreatic $\beta$-cells $[3,4]$. Although incretin secretion from gastrointestinal tract is not necessarily decreased in subjects with type 2 diabetes, it is likely that impaired incretin effect is another characteristic of type 2 diabetes [5-8]. It has been thought that the reduced incretin effect in type 2 diabetes is due to some defects in incretin receptor signaling rather than 
the decrease of blood concentration of incretin hormones. Previous reports showed that the expression levels of incretin receptor were decreased with hyperglycemia which likely leads to the impaired incretin effects found in diabetes $[8,9]$. Furthermore, the reduction of glucotoxicity with some glucose-lowering drugs restored the expression of incretin receptors in diabetic animals $[9,10]$ and improved incretin-induced insulin secretion in subjects with type 2 diabetes [11]. These data suggest that the durability of incretin-based therapy is likely dependent on the condition of glycemic control.

Alteration of lipid metabolism is one of the important characteristics that link the relationship between obesity and type 2 diabetes [12-15]. Abnormal lipid metabolism affects both insulin resistance and pancreatic $\beta$-cell function [15-17]. For example, prolonged exposure to fatty acid reduces pancreatic $\beta$-cell function and mass (i.e., lipotoxicity) $[15,18]$, whereas short-term exposure facilitates insulin secretion $[15,19]$. Recently, it was reported that while incretin secretion was comparable between obese and nonobese subjects with type 2 diabetes [20], glucose tolerance and obesity impaired the incretin effect independently of other factors [21]. Furthermore, Knop et al. showed that the incretin action was deteriorated even in obese participants who have normal glucose tolerance in spite of their insulin-resistant state and that the coexistence of obesity and hyperglycemia resulted in the additive attenuation of the incretin effect [22]. About the relationship between lipid control and incretin action, Kang et al. reported that elevated fatty acid contributes to impaired responsiveness to GLP-1, partially through the downregulation of GLP-1 receptor signaling and the improvement of lipid control by using fibrate in mouse models of obesity and diabetes [23]. Hodson et al. also showed that lipotoxicity disrupted incretin-regulated human $\beta$-cell connectivity, whereas GLP-1 and GIP recruit a robust coordinated subnetwork of $\beta$-cells [24]. Taken together, lipotoxicity is likely involved in the impaired response to incretin in pancreatic $\beta$-cells.

Dipeptidyl peptidase-4 (DPP-4) inhibitor suppresses activity of DPP-4, which is a splitting enzyme of incretin, and thereby increases serum levels of GLP-1 and GIP. Both incretins stimulate insulin secretion from $\beta$-cells in a glucose-dependent manner, and GLP-1 suppresses glucagon secretion from $\alpha$-cells. At present, DPP-4 inhibitor is very often used for the treatment of type 2 diabetes mellitus and exerts beneficial effects including glucose-lowering effect in many subjects with type 2 diabetes. Especially, DPP- 4 inhibitor is widely used in Japan, because the pathophysiology of type 2 diabetes in Japanese is primarily characterized by $\beta$ cell dysfunction and less insulin resistance compared with that in Caucasians [25]. However, to our knowledge, although previous reports have suggested the importance of weight management and diet/exercise therapy as the predictors for the durability of DPP-4 inhibitor [26, 27], it remains unclear which factors are closely associated with the durability of glucose-lowering effect by DPP-4 inhibitor. In this study, to examine which factors could influence the durability of DPP-4 inhibitor in subjects with type 2 diabetes, we analyzed retrospectively 212 outpatients who were treated with DPP-4 inhibitor for over 12 months without an addition or increase of other antidiabetes agents.

\section{Materials and Methods}

2.1. Subjects. The participants with type 2 diabetes who visited the outpatient clinic of diabetes at Kawasaki Medical School Hospital and had dipeptidyl peptidase-4 (DPP4) inhibitors, that is, sitagliptin $50 \mathrm{mg} /$ day, vildagliptin $100 \mathrm{mg} /$ day, and alogliptin $25 \mathrm{mg} /$ day, for over 1 year were eligible in this study. In addition, we excluded the subjects with the following states: (1) addition of other hypoglycemic agents, (2) increase of other glucose-lowering agents, (3) using steroid and/or immunosuppressive agents, and (4) suffering malignancy, acute and chronic inflammatory disease, and endocrine disease. The hospital ethics committee approved the study protocol (numbers 1183 and 1183-1), and informed consent was obtained from each person by showing it in our homepage after a full explanation of the study.

2.2. Examination Items. We monitored various clinical parameters such as HbAlc, body weight, total cholesterol, triglyceride, HDL cholesterol, and LDL cholesterol at baseline, 2, 4, 6, 8, 10, and 12 months after administrating DPP4 inhibitors. Blood samples were collected at various time points when the participants visited the hospital. To elucidate the factors associated with the efficacy of DPP-4 inhibitor in participants with type 2 diabetes, we divided the subjects into the effective group and the ineffective group and compared the participant backgrounds of the effective group with those of the ineffective group. It is noted here that effectiveness was defined as follows: when there was no change or decrease of $\mathrm{HbA} 1 \mathrm{c}$ level from baseline to 12 months in case of baseline $\mathrm{HbAlc}<7 \%(53 \mathrm{mmol} / \mathrm{mol})$ or when there was a decrease of $\mathrm{HbAlc}$ level from baseline to 12 months in case of baseline $\mathrm{HbAlc} \geq 7 \%(53 \mathrm{mmol} / \mathrm{mol})$.

2.3. Statistical Analyses. All analyses were performed by using JMP version 9. The comparison of clinical characteristics between the effective group and ineffective group was analyzed by employing the Mann-Whitney $U$ analysis and $\chi^{2}$ test. The Kruskal-Wallis test and Steel-Dwass test were used for comparisons of the values of HbAlc between baseline and after treatment. Multiple logistic regression method was used to analyze the factors independently contributing to the efficacy of DPP-4 inhibitor in participants with type 2 diabetes.

\section{Results}

3.1. Characteristics of the Study Participants. A total of 212 participants (men 126, 59\%; women 86, 41\%) were enrolled in this study. The baseline characteristics of the study participants were as follows: age $64.3 \pm 12.0$ years; body weight $65.4 \pm 15.8 \mathrm{~kg}$; BMI $25.1 \pm 5.1 \mathrm{~kg} / \mathrm{m}^{2}$; duration of diabetes $15.1 \pm 9.2$ years; $\mathrm{HbAlc} 7.7 \pm 1.2 \%(61 \pm 13.2 \mathrm{mmol} / \mathrm{mol})$; total cholesterol $182 \pm 34 \mathrm{mg} / \mathrm{dl}$; triglyceride $128 \pm 80 \mathrm{mg} / \mathrm{dl}$; HDL cholesterol, $55 \pm 14 \mathrm{mg} / \mathrm{dl}$; and LDL cholesterol 99 $\pm 27 \mathrm{mg} / \mathrm{dl}$. In addition, the prevalence rates of neuropathy, 


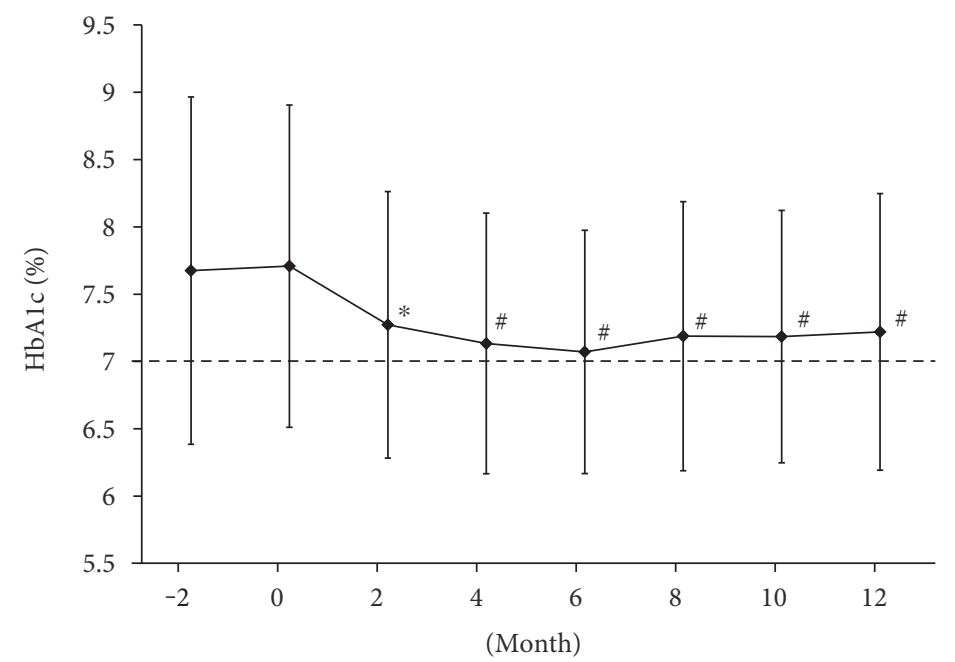

(a)

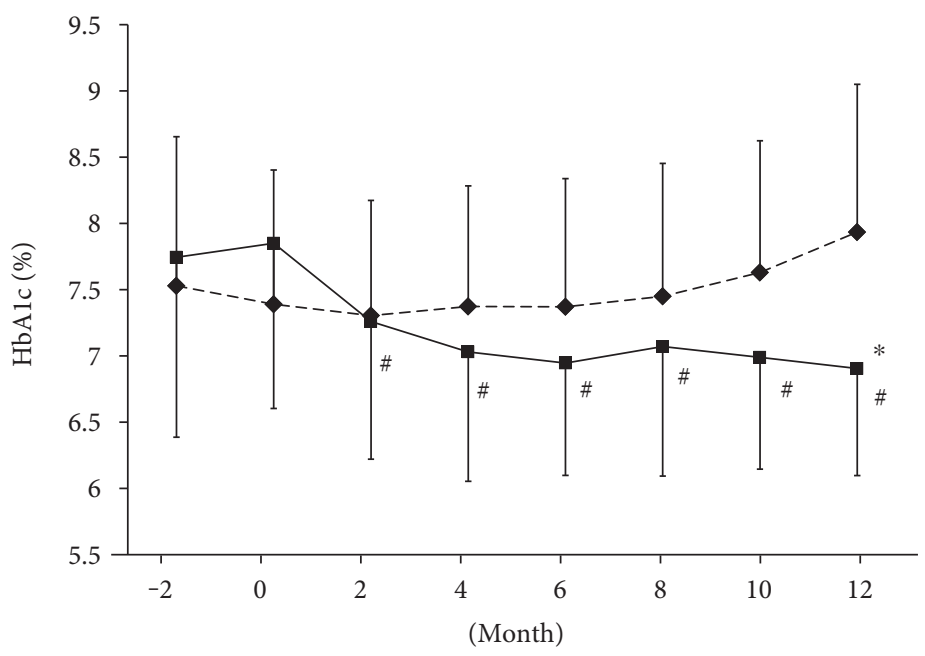

(b)

FIGURE 1: (a) Alteration of HbA1c levels after starting DPP-4 inhibitor in all participants (overall trend: $p<0.0001$ ). ${ }^{*} p<0.0005$ versus baseline; ${ }^{*} p<0.0001$ versus baseline. Data are shown as mean \pm SD. (b) Alteration of HbAlc levels after starting DPP-4 inhibitor in the effective group (solid line) (overall trend: $p<0.0001$ ) and the ineffective group (dashed line) (overall trend: $p<0.01$ ). ${ }^{*} p<0.0001$ versus the ineffective group at the same time point; ${ }^{\#} p<0.0001$ versus baseline in the effective group. Data are shown as mean \pm SD.

nephropathy, and retinopathy were $54 \%, 28 \%$, and $35 \%$, respectively. Therapeutic situation before the administration of DPP-4 inhibitor was as follows: diet only $15 \%$; sulfonylurea $35 \%$; glinide $15 \%$; biguanide $42 \%$; thiazolidine $39 \%$; aglucosidase inhibitor $26 \%$; insulin $15 \%$; monotherapy $26 \%$; and combination therapy 58\% (2 kinds of medicine $32 \%$; 3 kinds 22\%; and 4 kinds 5\%).

3.2. Glycemic Control after Administrating DPP-4 Inhibitors. DPP-4 inhibitors significantly lowered $\mathrm{HbA1c}$ levels 2 months after starting them compared to baseline in all participants in this study (Figure 1(a)). The change of HbAlc from baseline to 6 months later was $-0.7 \pm 1.1 \%$ $(7.7 \pm 12.0 \mathrm{mmol} / \mathrm{mol})$. HbAlc level was maintained even after reaching trough 6 months after starting the therapy (Figure 1(a)), and the change of HbAlc from baseline to 12 months later was $-0.5 \pm 1.1 \%(5.5 \pm 12.0 \mathrm{mmol} / \mathrm{mol})$.
3.3. Difference of Clinical Background between the Effective Group and Ineffective Group. There seemed to be a large variation among subjects in the durability of DPP-4 inhibitor. DPP-4 inhibitor exerted beneficial effect for 12 months in some subjects whereas it did not at all in other subjects. Therefore, we divided the subjects into the effective group $(n=147)$ or ineffective group $(n=65)$ and examined the alteration of glycemic control in each group. We regarded the subjects as the effective group, when there was no change or a decrease of HbAlc level from baseline to 12 months in case of baseline $\mathrm{HbA} 1 \mathrm{c}<7 \%$ or when there was a decrease of HbA1c level from baseline to 12 months in case of baseline $\mathrm{HbAlc} \geq 7 \%$. As the results, HbAlc level at every point after dosing in the effective group was significantly lower compared to baseline HbAlc (overall trend; $p<0.0001$ ) (Figure 1(b)). Conversely, HbA1c level after administrating in the ineffective group was significantly higher compared 
Journal of Diabetes Research

TABLE 1: Comparison of clinical background between the effective group and ineffective group in all participants with type 2 diabetes.

\begin{tabular}{|c|c|c|c|}
\hline Clinical parameter & Effective group & Ineffective group & $p$ value \\
\hline Number & 147 & 65 & \\
\hline Gender (men/women); $n(\%)$ & $90(61) / 57(39)$ & $36(55) / 29(45)$ & N.S. \\
\hline Age (year) & $65.8 \pm 10.5$ & $61.1 \pm 14.3$ & $<0.05$ \\
\hline BMI $\left(\mathrm{kg} / \mathrm{m}^{2}\right)$ & $25.1 \pm 5.0$ & $25.1 \pm 5.5$ & N.S. \\
\hline Duration of diabetes (year) & $15.8 \pm 9.6$ & $13.5 \pm 7.9$ & N.S. \\
\hline Family history of diabetes (\%) & 60 & 49 & N.S. \\
\hline \multirow{2}{*}{ Baseline HbAlc (\%) (mmol/mol) } & $7.8 \pm 1.2$ & $7.4 \pm 1.0$ & \multirow{2}{*}{$<0.01$} \\
\hline & $62 \pm 13.1$ & $57 \pm 10.9$ & \\
\hline Body weight change (kg) & $0.5 \pm 4.1$ & $0.8 \pm 3.5$ & 0.06 \\
\hline \multicolumn{4}{|l|}{ Total cholesterol (mg/dl) } \\
\hline Baseline & $182 \pm 33$ & $183 \pm 35$ & N.S. \\
\hline Average over 1 year & $176 \pm 27$ & $184 \pm 31$ & 0.08 \\
\hline \multicolumn{4}{|l|}{ Triglyceride (mg/dl) } \\
\hline Baseline & $120 \pm 65$ & $145 \pm 106$ & N.S. \\
\hline Average over 1 year & $120 \pm 50$ & $154 \pm 101$ & 0.09 \\
\hline \multicolumn{4}{|l|}{ HDL cholesterol (mg/dl) } \\
\hline Baseline & $56 \pm 14$ & $53 \pm 15$ & N.S. \\
\hline Average over 1 year & $55 \pm 13$ & $53 \pm 14$ & N.S. \\
\hline \multicolumn{4}{|l|}{ LDL cholesterol (mg/dl) } \\
\hline Baseline & $98 \pm 27$ & $101 \pm 27$ & N.S. \\
\hline Average over 1 year & $95 \pm 19$ & $100 \pm 23$ & N.S. \\
\hline
\end{tabular}

BMI: body mass index; LDL: low-density lipoprotein; HDL: high-density lipoprotein; N.S.: not significant. Data are described as mean \pm SD.

to baseline HbAlc (overall trend; $p<0.01$ ). The value of $\mathrm{HbA1c}$ in the effective group was significantly lower than that in the ineffective group 12 months after starting the therapy $(p<0.0001)$ (Figure $1(\mathrm{~b}))$.

To elucidate the factors related with the efficacy of DPP-4 inhibitors in subjects with type 2 diabetes, we analyzed the difference of clinical background between the effective group and ineffective group. Age $(p<0.05)$ and baseline HbAlc $(p<0.01)$ were significantly higher in the effective group than those in the ineffective group (Table 1). Although the baseline BMI was comparable between the groups, the value of body weight change tended to be lower in the effective group compared to that in the ineffective group (Table 1). Both the average of total cholesterol and average of triglyceride for over 1 year also tended to be lower in the effective group than those in the ineffective group (Table 1).

To elucidate the independent factors determining the efficacy of DPP-4 inhibitor in all participants with type 2 diabetes, we performed a multivariate regression analysis. Since there was some difference between the effective group and ineffective group in baseline $\mathrm{HbA1c}$, body weight change, average total cholesterol, and average triglyceride (Table 1), we included baseline HbAlc, body weight change, average total cholesterol, and average triglyceride as independent variables. In addition, to avoid the possible influence of age or gender, we included age and gender as independent variables as well. As shown in Table 2, even after adjustment with age and gender, average triglyceride and basal $\mathrm{HbAlc}$ were independent factors contributing to the efficacy of DPP-4 inhibitor in subjects with type 2 diabetes.
TABLE 2: Multiple logistic regression analysis of factors related with efficacy of DPP-4 inhibitor in all participants with type 2 diabetes.

\begin{tabular}{lccc}
\hline Clinical parameter & Odds ratio & $95 \%$ CI & $p$ value \\
\hline Baseline HbA1c & 1.69 & {$[1.217,2.472]$} & 0.004 \\
Average triglyceride & 0.99 & {$[0.990,0.999]$} & 0.024 \\
Age & 1.03 & {$[1.000,1.064]$} & 0.048 \\
Average total cholesterol & 0.99 & {$[0.979,1.003]$} & 0.145 \\
Gender & 1.28 & {$[0.655,2.508]$} & 0.466 \\
Body weight change & 1.01 & {$[0.934,1.104]$} & 0.731 \\
\hline
\end{tabular}

Dependent variable: effective group. Gender: 0 , female; 1 , male. Odds ratio: per 1-increment increase in variable. CI: confidence interval.

These data suggest that triglyceride management is very important to maintain the durability of DPP-4 inhibitor.

Next, we examined whether there were significant differences in the clinical background between the effective group and ineffective group in the presence or absence of obesity. In the nonobese group (BMI $\left.<25 \mathrm{~kg} / \mathrm{m}^{2}\right)(n=124)$, there was no difference between the effective group and ineffective group except for baseline $\operatorname{HbA1c}(p=0.02$; Table 3$)$. In contrast, in the obese group $\left(\mathrm{BMI} \geq 25 \mathrm{~kg} / \mathrm{m}^{2}\right)(n=88)$, age was more advanced in the effective group compared with that in the ineffective group $(p=0.0008$; Table 4$)$. Conversely, average total cholesterol $(p=0.04)$, baseline triglyceride $(p=0.02)$, and average triglyceride $(p=0.005)$ were lower in the effective group than those in the ineffective group (Table 4 ). 
TABLE 3: Comparison of clinical background between the effective group and ineffective group in nonobese subjects with type 2 diabetes $\left(\mathrm{BMI}<25 \mathrm{~kg} / \mathrm{m}^{2}\right)$.

\begin{tabular}{|c|c|c|c|}
\hline Clinical parameter & Effective group & Ineffective group & $p$ value \\
\hline Number & 89 & 35 & \\
\hline Gender (men/women); $n$ (\%) & $56(63) / 33(37)$ & $18(51) / 17(49)$ & N.S. \\
\hline Age (year) & $68.9 \pm 9.4$ & $69.0 \pm 10.2$ & N.S. \\
\hline BMI $\left(\mathrm{kg} / \mathrm{m}^{2}\right)$ & $22.1 \pm 1.9$ & $21.4 \pm 2.6$ & N.S. \\
\hline Duration of diabetes (year) & $17.8 \pm 9.9$ & $15.2 \pm 8.4$ & N.S. \\
\hline Family history of diabetes (\%) & 66 & 44 & N.S. \\
\hline \multirow{2}{*}{ Baseline HbAlc (\%) (mmol/mol) } & $7.7 \pm 1.0$ & $7.1 \pm 0.7$ & \multirow{2}{*}{0.0003} \\
\hline & $61 \pm 10.9$ & $54 \pm 7.7$ & \\
\hline Body weight change (kg) & $0.5 \pm 2.4$ & $1.0 \pm 2.7$ & N.S. \\
\hline \multicolumn{4}{|l|}{ Total cholesterol (mg/dl) } \\
\hline Baseline & $180 \pm 32$ & $173 \pm 32$ & N.S. \\
\hline Average over 1 year & $175 \pm 29$ & $179 \pm 31$ & N.S. \\
\hline \multicolumn{4}{|l|}{ Triglyceride (mg/dl) } \\
\hline Baseline & $109 \pm 59$ & $96 \pm 44$ & N.S. \\
\hline Average over 1 year & $108 \pm 48$ & $108 \pm 46$ & N.S. \\
\hline \multicolumn{4}{|l|}{ HDL cholesterol (mg/dl) } \\
\hline Baseline & $58 \pm 15$ & $56 \pm 17$ & N.S. \\
\hline Average over 1 year & $57 \pm 14$ & $56 \pm 16$ & N.S. \\
\hline \multicolumn{4}{|l|}{ LDL cholesterol (mg/dl) } \\
\hline Baseline & $95 \pm 25$ & $93 \pm 21$ & N.S. \\
\hline Average over 1 year & $93 \pm 20$ & $95 \pm 22$ & N.S. \\
\hline
\end{tabular}

BMI: body mass index; HDL: high-density lipoprotein; LDL: low-density lipoprotein; N.S.: not significant. Data are described as mean \pm SD.

TABLE 4: Comparison of clinical background between the effective group and ineffective group in obese subjects with type 2 diabetes $\left(\mathrm{BMI} \geq 25 \mathrm{~kg} / \mathrm{m}^{2}\right)$.

\begin{tabular}{|c|c|c|c|}
\hline Clinical parameter & Effective group & Ineffective group & $p$ value \\
\hline Number & 58 & 30 & \\
\hline Gender (men/women); $n(\%)$ & $34(59) / 24(41)$ & $18(60) / 12(40)$ & N.S. \\
\hline Age (year) & $60.9 \pm 10.5$ & $51.8 \pm 12.8$ & 0.0008 \\
\hline BMI $\left(\mathrm{kg} / \mathrm{m}^{2}\right)$ & $29.6 \pm 4.9$ & $29.4 \pm 4.8$ & N.S. \\
\hline Duration of diabetes (year) & $12.7 \pm 8.3$ & $11.3 \pm 6.9$ & N.S. \\
\hline Family history of diabetes (\%) & 51 & 55 & N.S. \\
\hline \multirow{2}{*}{ Baseline $\mathrm{HbAlc}(\%)(\mathrm{mmol} / \mathrm{mol})$} & $8.0 \pm 1.6$ & $7.8 \pm 1.2$ & \multirow{2}{*}{ N.S. } \\
\hline & $64 \pm 17.5$ & $62 \pm 13.1$ & \\
\hline Body weight change $(\mathrm{kg})$ & $0.5 \pm 5.7$ & $0.7 \pm 4.3$ & N.S. \\
\hline \multicolumn{4}{|l|}{ Total cholesterol (mg/dl) } \\
\hline Baseline & $185 \pm 35$ & $196 \pm 35$ & N.S. \\
\hline Average over 1 year & $177 \pm 23$ & $190 \pm 29$ & 0.04 \\
\hline \multicolumn{4}{|l|}{ Triglyceride (mg/dl) } \\
\hline Baseline & $139 \pm 70$ & $202 \pm 127$ & 0.02 \\
\hline Average over 1 year & $137 \pm 49$ & $209 \pm 120$ & 0.005 \\
\hline \multicolumn{4}{|l|}{ HDL cholesterol (mg/dl) } \\
\hline Baseline & $53 \pm 12$ & $50 \pm 12$ & N.S. \\
\hline Average over 1 year & $52 \pm 11$ & $50 \pm 11$ & N.S. \\
\hline \multicolumn{4}{|l|}{ LDL cholesterol (mg/dl) } \\
\hline Baseline & $103 \pm 31$ & $110 \pm 30$ & N.S. \\
\hline Average over 1 year & $98 \pm 19$ & $106 \pm 24$ & N.S. \\
\hline
\end{tabular}

BMI: body mass index; LDL: low-density lipoprotein; HDL: high-density lipoprotein; N.S.: not significant. Data are described as mean \pm SD. 
TABLE 5: Multiple logistic regression analysis of factors related with efficacy of DPP-4 inhibitor in obese subjects with type 2 diabetes $\left(\mathrm{BMI} \geq 25 \mathrm{~kg} / \mathrm{m}^{2}\right)$.

\begin{tabular}{lccc}
\hline Clinical parameter & Odds ratio & $95 \%$ CI & $p$ value \\
\hline Age & 1.06 & {$[1.010,1.107]$} & 0.019 \\
Average triglyceride & 0.99 & {$[0.984,0.999]$} & 0.033 \\
Average total cholesterol & 0.98 & {$[0.962,1.005]$} & 0.152 \\
Gender & 1.26 & {$[0.438,3.688]$} & 0.665 \\
\hline
\end{tabular}

Odds ratio: per 1-increment increase in variable. CI: confidence interval.

To elucidate the independent factors determining the efficacy of DPP-4 inhibitor in the obese group with type 2 diabetes, we performed a multivariate regression analysis. Since there was difference between the effective group and ineffective group in baseline $\mathrm{HbAlc}$, body weight change, average total cholesterol, and average triglyceride (Table 4), we included average total cholesterol and average triglyceride as independent variables. In addition, to avoid the possible influence of age or gender, we included age and gender as independent variables as well. As shown in Table 5, even after adjustment with age and gender, average triglyceride level was an independent factor contributing to the efficacy of DPP-4 inhibitor in the obese group with type 2 diabetes. These data suggest that triglyceride management is particularly important in obese subjects to maintain the durability of DPP-4 inhibitor.

\section{Discussion}

The final targets of diabetes treatment are extension of healthy life expectancy and preservation of the quality of life. It is necessary to keep favorable glycemic control in order to achieve these goals. A Diabetes Outcome Progression Trial (ADOPT) indicated that glucose-lowering effect by monotherapy (rosiglitazone, metformin or glyburide) was attenuated over the long term because of gradual decline of pancreatic $\beta$-cell function, although the efficacy of rosiglitazone was relatively preserved compared to that of other drugs $[28,29]$. It has been shown that incretin-related drugs such as DPP-4 inhibitors preserve $\beta$-cell function and keep superior glucose-lowering effect compared with sulfonylurea [30-32]. Based on these backgrounds, incretin-related drugs have become a central agent in insulin secretagogues. Although recent studies reported that inadequate compliance with diet/exercise therapy and weight gain may be associated with an increase of $\mathrm{HbAlc}$ over time during treatment with DPP-4 inhibitor [26, 27], it is poorly understood about which factors are closely associated with the durability of glucoselowering effect by DPP-4 inhibitor.

In this study, the effective group showed more advanced age, higher baseline $\mathrm{HbAlc}$, tendency of smaller weight gain, lower average total cholesterol, and lower average triglyceride compared with the ineffective group. Multivariate regression analysis after adjustment with age and gender demonstrated that average triglyceride and basal $\mathrm{HbAlc}$ were independent factors determining the durability of DPP-4 inhibitor in subjects with type 2 diabetes. Furthermore, multivariate regression analysis after adjustment with age and gender in only obese subjects demonstrated that only average triglyceride level was an independent factor determining the durability of DPP-4 inhibitor. To the best of our knowledge, the present study is the first report which revealed the importance of lipid control in order to maintain the efficacy of DPP-4 inhibitor especially in the obese group with type 2 diabetes. The present study showed that when the value of average triglyceride was decreased by 20,50 , and $100 \mathrm{mg} / \mathrm{dl}$, odds ratios were $0.86,0.69$, and 0.48 in all cases. Similarly, when the value of average triglyceride was decreased by 20,50 , and $100 \mathrm{mg} / \mathrm{dl}$, odds ratios were $0.86,0.68$, and 0.46 in obese subjects. These data also clearly suggest the importance of triglyceride management for the durability of DPP-4 inhibitor in subjects with type 2 diabetes.

Kang et al. showed that GLP-1 receptor mRNA expression and GLP-1-stimulated insulin secretion were reduced in palmitate-treated rodent insulinoma cell lines and mouse islets [22], and GLP-1 receptor mRNA expression was restored in isolated islet in $d b / d b$ mice treated with bezafibrate for 2 weeks compared to untreated $d b / d b$ mice [23]. Moreover, lipid lowering by bezafibrate enhanced the efficacy of DPP-4 inhibitor des-fluoro-sitagliptin to improve glucose tolerance in $d b / d b$ mice with amelioration of $\beta$-cell function [23]. Furthermore, previous reports revealed that fatty acid-mediated downregulation of connexin36 expression $[24,33]$, which consolidates the physiological and biochemical connectivity of neighboring $\beta$-cells [34] and disrupts incretin-regulated human $\beta$-cell connectivity [24]. Abnormality of lipid metabolism might decrease incretin effect at least partly through these mechanisms in $\beta$-cells. In fact, obesity is an independently predicted factor of decreased incretin action, and integration of obesity and hyperglycemia additively impair insulin secretion by incretin [21,22]. Furthermore, previous articles showed that the short-term [35-37] and long-term [26] glucose-lowering effects by DPP-4 inhibitor were less in obese people with type 2 diabetes. In the present study as well as the past reports [26,27], body weight gain tended to decrease the glucose-lowering effect over time during treatment with DPP-4 inhibitor. But multivariate regression analysis, which included both body weight change and average triglyceride as independent variables, demonstrated that average triglyceride was an independent factor determining the durability of DPP-4 inhibitor in subjects with type 2 diabetes. Moreover, there was a substantial difference between obese and nonobese individuals in the influence of triglyceride on glucose-lowering effect by DPP- 4 inhibitor. These results indicate the importance of triglyceride management during treatment with DPP-4 inhibitor in obese subjects rather than nonobese subjects with type 2 diabetes.

There are some limitations to interpret the results of this study. First, DPP-4 inhibitor improves glycemic control through the action on pancreatic islets by increment of incretin hormone levels in the physiological range. Therefore, although we speculate that hypertriglyceridemia might impair the incretin action in the pancreatic islets, we could not examine the relationship between triglyceride level and islet function. Second, we could not clarify the relation between the efficacy of DPP-4 inhibitor and that of TG- 
lowering drugs (e.g., fibrate and eicosapentaenoic acid), because there were only a few people $(18 / 212 ; 8.5 \%)$ who took these drugs. Third, the previous reports showed that DPP-4 inhibitor is effective in patients with type 2 diabetes with high serum eicosapentaenoic acid concentrations $[36,38]$. Although we should conduct the analysis including the information related with dietary habits, we could not analyze this point owing to a retrospective study. Fourth, because blood samples were collected at various time points when the participants visited the hospital, the threshold of triglyceride level for the durability of efficacy of DPP-4 inhibitor remains uncertain. Further study would be necessary to demonstrate these points.

Taken together, the data in this study suggest that inadequate triglyceride management worsens the durability of DPP-4 inhibitor in subjects, particularly in obese subjects, with type 2 diabetes mellitus. Therefore, in order to maintain glucose-lowering effect by DPP-4 inhibitor for a long time, it is necessary to keep strict triglyceride management especially in obese subjects with type 2 diabetes.

\section{Conflicts of Interest}

All the other authors declare that there is no conflict of interests regarding the publication of this article.

\section{Acknowledgments}

Hideaki Kaneto has received honoraria for lectures and received scholarship grants from Sanofi, Novo Nordisk, Lilly, Nippon Boehringer Ingelheim Co., MSD, Mochida Pharmaceutical Co., Kyowa Hakko Kirin Co., Takeda, Ono Pharma, Daiichi Sankyo, Sumitomo Dainippon Pharma, Mitsubishi Tanabe Pharma, Pfizer, Kissei Pharma, AstraZeneca, and Astellas. Kohei Kaku has been an advisor to, received honoraria for lectures from, and received scholarship grants from Novo Nordisk Pharma, Takeda, Sumitomo Dainippon Pharma, Mitsubishi Tanabe Pharma, Nippon Boehringer Ingelheim Co., Chugai, Daiichi Sankyo, Taisho Toyama Pharmaceutical Co., Astellas, AstraZeneca, Ono Pharma, Kissei Pharmaceutical Co., Sanwa Kagaku Kenkyusho Co., Novartis, MSD, Kowa, Fujifilm Pharma, and Sanofi.

\section{References}

[1] U.K. prospective diabetes study 16. Overview of 6 years' therapy of type II diabetes: a progressive disease. U.K. prospective diabetes study group," Diabetes, vol. 44, no. 11, pp. 1249-1258, 1995.

[2] P. A. Halban, K. S. Polonsky, D. W. Bowden et al., "Beta-cell failure in type 2 diabetes: postulated mechanisms and prospects for prevention and treatment," The Journal of Clinical Endocrinology and Metabolism, vol. 99, no. 6, pp. 1983-1992, 2014.

[3] L. L. Baggio and D. J. Drucker, "Biology of incretins: GLP-1 and GIP," Gastroenterology, vol. 132, no. 6, pp. 21312157, 2007.
[4] J. J. Holst, T. Vilsboll, and C. F. Deacon, "The incretin system and its role in type 2 diabetes mellitus," Molecular and Cellular Endocrinology, vol. 297, no. 1-2, pp. 127-136, 2009.

[5] J. J. Meier and M. A. Nauck, "Is the diminished incretin effect in type 2 diabetes just an epi-phenomenon of impaired betacell function?" Diabetes, vol. 59, no. 5, pp. 1117-1125, 2010.

[6] M. A. Nauck, I. Vardarli, C. F. Deacon, J. J. Holst, and J. J. Meier, "Secretion of glucagon-like peptide-1 (GLP-1) in type 2 diabetes: what is up, what is down?" Diabetologia, vol. 54, no. 1, pp. 10-18, 2011.

[7] S. Lee, D. Yabe, K. Nohtomi et al., "Intact glucagonlike peptide-1 levels are not decreased in Japanese patients with type 2 diabetes," Endocrine Journal, vol. 57, no. 2, pp. 119-126, 2010.

[8] N. Abrahamsen and E. Nishimura, "Regulation of glucagon and glucagon-like peptide-1 receptor messenger ribonucleic acid expression in cultured rat pancreatic islets by glucose, cyclic adenosine 3',5'-monophosphate, and glucocorticoids," Endocrinology, vol. 136, no. 4, pp. 1572-1578, 1995.

[9] G. Xu, H. Kaneto, D. R. Laybutt et al., "Downregulation of GLP-1 and GIP receptor expression by hyperglycemia: possible contribution to impaired incretin effects in diabetes," Diabetes, vol. 56, no. 6, pp. 1551-1558, 2007.

[10] S. Kawashima, T. A. Matsuoka, H. Kaneto et al., "Effect of alogliptin, pioglitazone and glargine on pancreatic beta-cells in diabetic db/db mice," Biochemical and Biophysical Research Communications, vol. 404, no. 1, pp. 534-540, 2011.

[11] P. V. Hojberg, M. Zander, T. Vilsboll et al., "Near normalisation of blood glucose improves the potentiating effect of GLP-1 on glucose-induced insulin secretion in patients with type 2 diabetes," Diabetologia, vol. 51, no. 4, pp. 632-640, 2008.

[12] A. E. Butler, J. Janson, S. Bonner-Weir, R. Ritzel, R. A. Rizza, and P. C. Butler, "Beta-cell deficit and increased beta-cell apoptosis in humans with type 2 diabetes," Diabetes, vol. 52, no. 1 , pp. 102-110, 2003.

[13] G. Paolisso, P. A. Tataranni, J. E. Foley, C. Bogardus, B. V. Howard, and E. Ravussin, "A high concentration of fasting plasma non-esterified fatty acids is a risk factor for the development of NIDDM," Diabetologia, vol. 38, no. 10, pp. 1213-1217, 1995.

[14] J. D. McGarry and R. L. Dobbins, "Fatty acids, lipotoxicity and insulin secretion," Diabetologia, vol. 42, no. 2, pp. 128138, 1999.

[15] A. Giacca, C. Xiao, A. I. Oprescu, A. C. Carpentier, and G. F. Lewis, "Lipid-induced pancreatic beta-cell dysfunction: focus on in vivo studies," American Journal of Physiology. Endocrinology and Metabolism, vol. 300, no. 2, pp. E255-E262, 2011.

[16] F. Karpe, J. R. Dickmann, and K. N. Frayn, "Fatty acids, obesity, and insulin resistance: time for a reevaluation," Diabetes, vol. 60, no. 10, pp. 2441-2449, 2011.

[17] Y. Lee, H. Hirose, M. Ohneda, J. H. Johnson, J. D. McGarry, and R. H. Unger, "Beta-cell lipotoxicity in the pathogenesis of non-insulin-dependent diabetes mellitus of obese rats: impairment in adipocyte-beta-cell relationships," Proceedings of the National Academy of Sciences of the United States of America, vol. 91, no. 23, pp. 10878-10882, 1994.

[18] Y. P. Zhou and V. E. Grill, "Long-term exposure of rat pancreatic islets to fatty acids inhibits glucose-induced insulin secretion and biosynthesis through a glucose fatty acid cycle," The Journal of Clinical Investigation, vol. 93, no. 2, pp. 870-876, 1994. 
[19] S. R. Crespin, W. B. Greenough 3rd, and D. Steinberg, "Stimulation of insulin secretion by long-chain free fatty acids. A direct pancreatic effect," The Journal of Clinical Investigation, vol. 52, no. 8, pp. 1979-1984, 1973.

[20] J. Kozawa, K. Okita, A. Imagawa et al., "Similar incretin secretion in obese and non-obese Japanese subjects with type 2 diabetes," Biochemical and Biophysical Research Communications, vol. 393, no. 3, pp. 410-413, 2010.

[21] E. Muscelli, A. Mari, A. Casolaro et al., "Separate impact of obesity and glucose tolerance on the incretin effect in normal subjects and type 2 diabetic patients," Diabetes, vol. 57, no. 5, pp. 1340-1348, 2008.

[22] F. K. Knop, K. Aaboe, T. Vilsboll et al., "Impaired incretin effect and fasting hyperglucagonaemia characterizing type 2 diabetic subjects are early signs of dysmetabolism in obesity," Diabetes, Obesity and Metabolism, vol. 14, no. 6, pp. 500-510, 2012.

[23] Z. F. Kang, Y. Deng, Y. Zhou et al., "Pharmacological reduction of NEFA restores the efficacy of incretin-based therapies through GLP-1 receptor signalling in the beta cell in mouse models of diabetes," Diabetologia, vol. 56, no. 2, pp. 423-433, 2013.

[24] D. J. Hodson, R. K. Mitchell, E. A. Bellomo et al., "Lipotoxicity disrupts incretin-regulated human beta cell connectivity," The Journal of Clinical Investigation, vol. 123, no. 10, pp. 41824194, 2013.

[25] Y. Seino, H. Kuwata, and D. Yabe, "Incretin-based drugs for type 2 diabetes: focus on East Asian perspectives," Journal of Diabetes Investigation, vol. 7, Supplement 1, pp. 102109, 2016.

[26] A. Kanamori and I. Matsuba, "Factors associated with reduced efficacy of sitagliptin therapy: analysis of 93 patients with type 2 diabetes treated for 1.5 years or longer," Journal of Clinical Medicine Research, vol. 5, no. 3, pp. 217-221, 2013.

[27] H. Maeda, A. Kubota, A. Kanamori, Y. Tanaka, Y. Terauchi, and I. Matsuba, "Long-term efficacy and safety of sitagliptin in the treatment of Japanese type 2 diabetes (ASSET-K1) to a target of HbAlc <7\%," Journal of Endocrinological Investigation, vol. 36, no. 8, pp. 568-573, 2013.

[28] S. E. Kahn, S. M. Haffner, M. A. Heise et al., "Glycemic durability of rosiglitazone, metformin, or glyburide monotherapy," The New England Journal of Medicine, vol. 355, no. 23, pp. 2427-2443, 2006.

[29] S. E. Kahn, J. M. Lachin, B. Zinman et al., "Effects of rosiglitazone, glyburide, and metformin on beta-cell function and insulin sensitivity in ADOPT," Diabetes, vol. 60, no. 5, pp. 1552-1560, 2011.

[30] B. Gallwitz, J. Guzman, F. Dotta et al., "Exenatide twice daily versus glimepiride for prevention of glycaemic deterioration in patients with type 2 diabetes with metformin failure (EUREXA): an open-label, randomised controlled trial," Lancet, vol. 379, no. 9833, pp. 2270-2278, 2012.

[31] T. Seck, M. Nauck, D. Sheng et al., "Safety and efficacy of treatment with sitagliptin or glipizide in patients with type 2 diabetes inadequately controlled on metformin: a 2-year study," International Journal of Clinical Practice, vol. 64, no. 5, pp. 562-576, 2010.

[32] B. Gallwitz, J. Rosenstock, T. Rauch et al., "2-year efficacy and safety of linagliptin compared with glimepiride in patients with type 2 diabetes inadequately controlled on metformin: a randomised, double-blind, non-inferiority trial," Lancet, vol. 380, no. 9840, pp. 475-483, 2012.
[33] F. Allagnat, F. Alonso, D. Martin, A. Abderrahmani, G. Waeber, and J. A. Haefliger, "ICER-1gamma overexpression drives palmitate-mediated connexin36 down-regulation in insulin-secreting cells," The Journal of Biological Chemistry, vol. 283, no. 9, pp. 5226-5234, 2008.

[34] V. Cigliola, V. Chellakudam, W. Arabieter, and P. Meda, "Connexins and beta-cell functions," Diabetes Research and Clinical Practice, vol. 99, no. 3, pp. 250-259, 2013.

[35] H. Maeda, A. Kubota, Y. Tanaka, Y. Terauchi, and I. Matsuba, "The safety, efficacy and predictors for HbAlc reduction of sitagliptin in the treatment of Japanese type 2 diabetes," Diabetes Research and Clinical Practice, vol. 95, no. 1, pp. e20-e22, 2012.

[36] T. Senmaru, M. Fukui, K. Kobayashi et al., "Dipeptidylpeptidase IV inhibitor is effective in patients with type 2 diabetes with high serum eicosapentaenoic acid concentrations," Journal of Diabetes Investigation, vol. 3, no. 6, pp. 498-502, 2012.

[37] Y. Bando, H. Kanehara, K. Aoki, A. Hisada, D. Toya, and N. Tanaka, "Obesity may attenuate the HbAlc-lowering effect of sitagliptin in Japanese type 2 diabetic patients," Journal of Diabetes Investigation, vol. 3, no. 2, pp. 170-174, 2012.

[38] M. Iwasaki, F. Hoshian, T. Tsuji et al., "Predicting efficacy of dipeptidyl peptidase- 4 inhibitors in patients with type 2 diabetes: association of glycated hemoglobin reduction with serum eicosapentaenoic acid and docosahexaenoic acid levels," Journal of Diabetes Investigation, vol. 3, no. 5, pp. 464-467, 2012. 


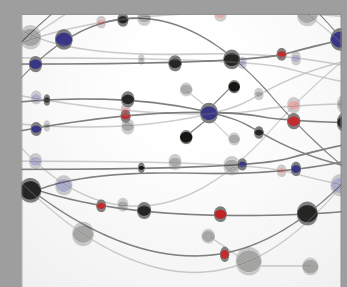

The Scientific World Journal
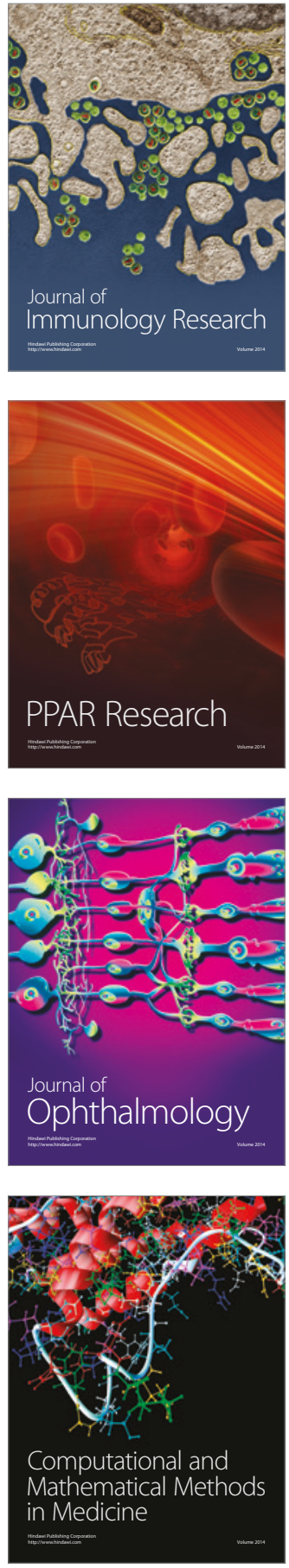

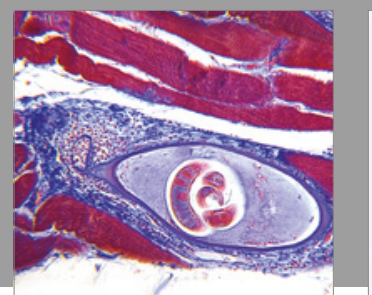

Gastroenterology Research and Practice
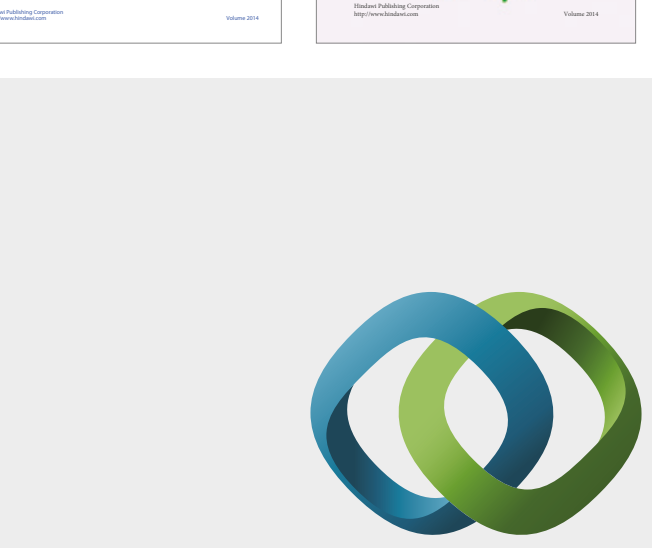

\section{Hindawi}

Submit your manuscripts at

https://www.hindawi.com
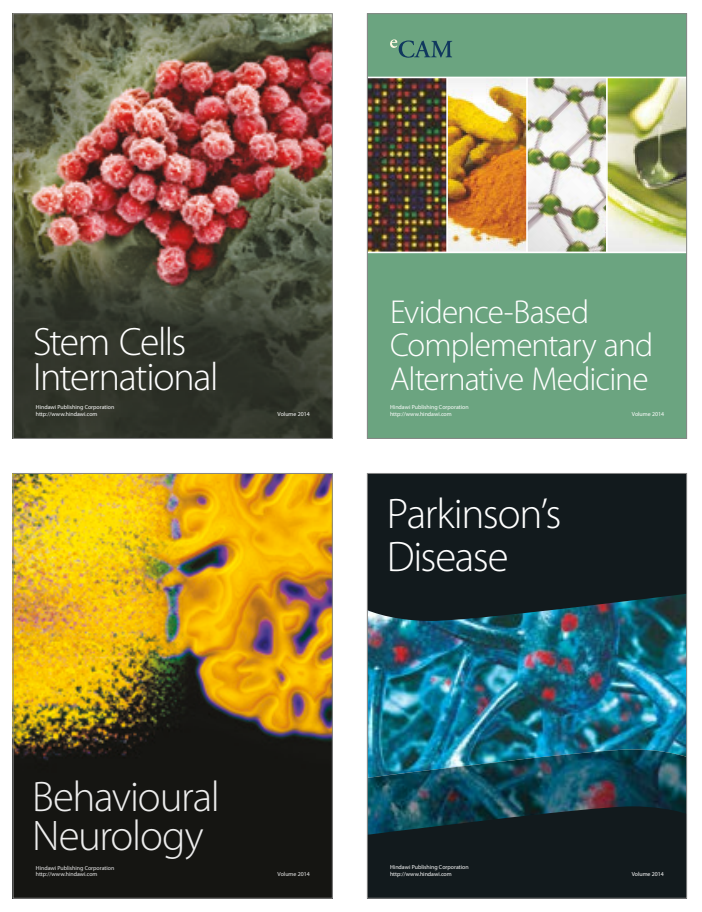
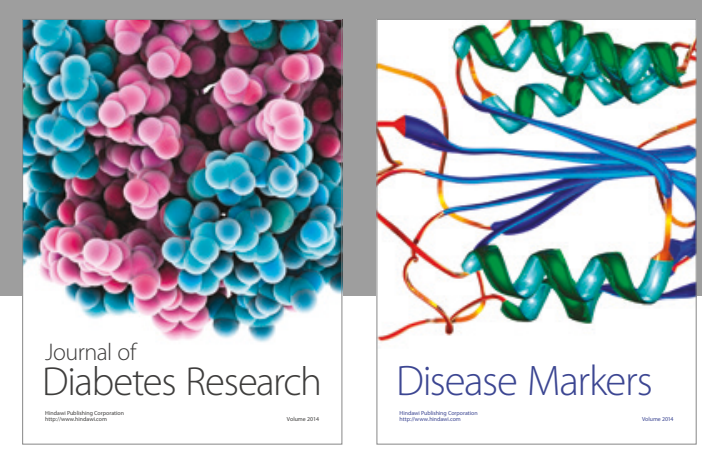

Disease Markers
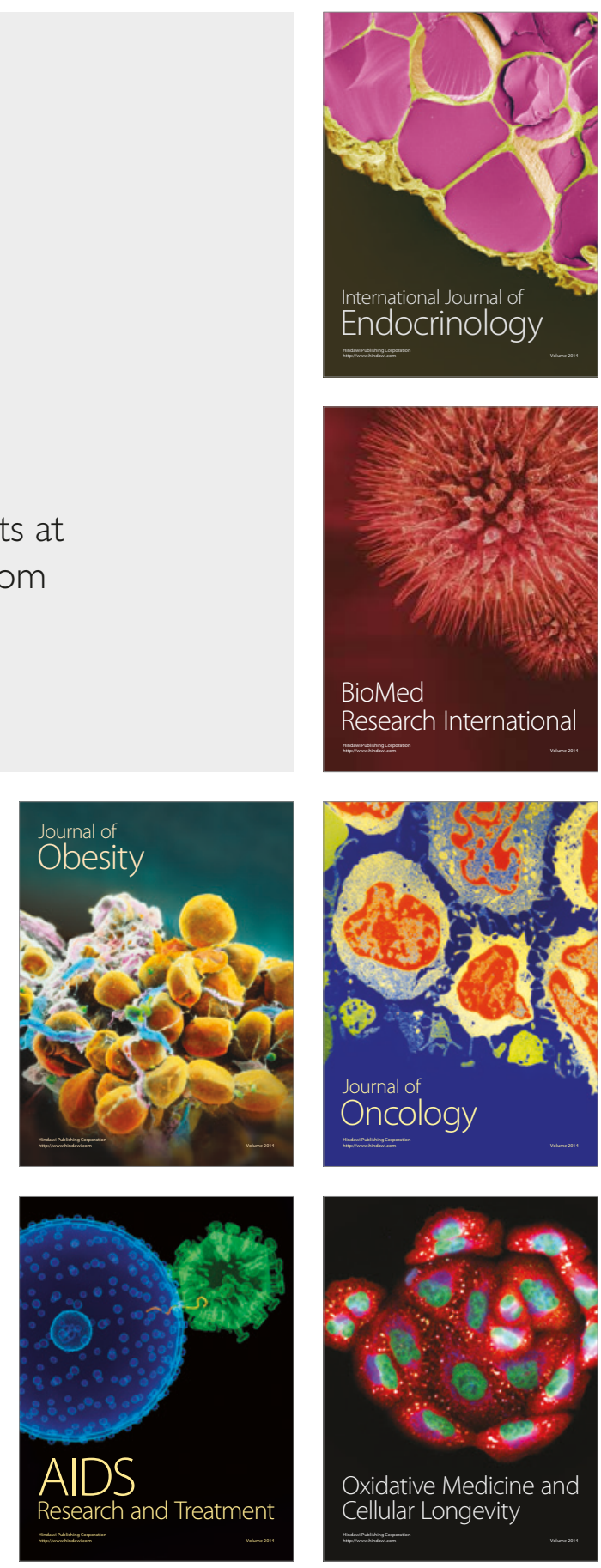